REVISTA DE LITERATURA E CULTURA RUSSA

\title{
Poiesis como tomada de decisão: Chklóvski, Tyniánov, Bakhtin
}

Poiesis as a DecisionMaking: Shklovsky, Tynianov, Bakhtin

Autor: Peter Steiner Edição: RUS Vol. 11. № 16

Data: Setembro 2020 


\section{Poiesis como tomada de decisão: Chklóvski, Tyniánov, Bakhtin ${ }^{1}$}

Resumo: A ciência da decisão é uma disciplina relativamente nova: é o produto da imbricação entre matemática, psicologia, economia e outros ramos do saber. Ela estuda como as pessoas fazem suas escolhas e procura fornecer um "quadro racional de escolha entre alternativas possíveis quando as consequências resultantes de tal ação são imprecisamente conhecidas". Meu artigo aborda as teorias de Viktor Chklóvski e lúri Tyniánov resumindo como esses dois membros da Sociedade para o Estudo da Linguagem Poética (OPOIAZ), de São Petersburgo, consideravam o escritor um agente racional que almejava um objetivo específico e os meios disponíveis para obtê-lo. Para concluir, justaponho a conceituação formalista de criatividade poética à visão de Mikhail Bakhtin sobre o mesmo assunto, argumentando que a maneira como ele concebe as estratégias disponíveis ao autor literário se adequa a pressupostos da chamada "racionalidade interativa".

\begin{abstract}
Decision science is a relatively new discipline: the product of a cross-pollination among mathematics, psychology, economy and a few other branches of knowledge. It studies how humans make their choices and purports to provide a "rational framework for choosing between alternative courses of action when the consequences resulting from this choice are imperfectly known." My paper deals with the theories of Viktor Shklovsky and lurii Tynianov outlining how these two members of the Petersburg "Society for the Study of Poetic Language"(OPOIAZ) conceived of the writer as a rational agent pursuing a specific goal, and of the means at his/her disposal to attain it. To conclude, I will juxtapose the Formalists' conceptualization of poetic creativity to Mikhail Bakhtin's view on the subject arguing that the way he conceives of the strategies available to the literary author fit the label of "interactive rationality."
\end{abstract}

Palavras-chave: Teoria da decisão; Racionalidade interativa; Chklóvski; Tyniánov; Bakhtin

Keywords: Decision theory; Interactive rationality; Shklovsky; Tynianov; Bakhtin 
"E quando você tiver decidido, então confie em Allá"

Al-Qur'an 3:159
* Professor Emérito de Literatura Eslava University of Pennsylvania, Russian and East European Studies. Autor, entre outros, do livro Russian Formalism: A Metapoetics; psteiner@sas.upenn.edu

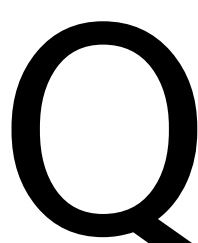

ualquer um que já tenha tentado escrever uma obra literaria (e mesmo quem não tenha) sabe perfeitamente quão fascinante é essa atividade. $O$ aspirante a escritor deve não apenas escolher entre uma miríade de possibilidades de composição, mas também discutir seus textos com aqueles que compartilham de objetivo similar e, paralelamente a isso, também deve situar sua produção dentro do universo discursivo amplo de uma determinada época e, no caso de utopistas, até mesmo para além de seu tempo. Tudo isso é feito, imagine você, sem qualquer garantia de que a obra nascente desencadeará em seus leitores o efeito estético desejado. Pensada por este ângulo, a criatividade literária pode ser analisada produtivamente pela ciência da decisão - uma disciplina relativamente nova, resultante de uma mistura fecunda entre matemática, psicologia, economia e alguns outros ramos do saber. Seu foco é descobrir como as pessoas fazem escolhas e se encarregam de fornecer um "quadro racional de escolhas possíveis, quando as consequências decorrentes dessa escolha são insuficientemente conhecidas". ${ }^{2}$

Isso parece tentador, mas quão factível é este processo? Os littérateurs [literatos], afinal de contas, se valem com frequência da excentricidade como um traço distintivo e as razões explícitas que eles apresentam para se engajarem na arte verbal parecem fantasiosas demais para serem tratadas, ao menos por enquanto, de maneira sistemática. A fim de evitar esse obs-

10 texto original do artigo foi publicado em russo, em 2019, na revista Slovo.ru: baltic accent, vol. 10, no. 2, p. 6-25. doi: 10.5922/2225-5346-2019-2-1. A presente tradução foi realizada a partir da versão para o inglês, aceita pela revista Poetics Today, mas ainda não publicada.

2 NORTH, Warner D. "A Tutorial Introduction to Decision Theory," IEEE Transactions on Systems Science and Cybernetics, vol. SSC-4, no. 3; setembro, 1968, p. 200. 
táculo, deixe-me enfrentar meu propósito indiretamente: por meio da metateorização. ${ }^{3}$ No que se segue, eu abordo as teorias da produção literária elaboradas nas primeiras décadas do século passado por uma tríade de críticos russos famosos para argumentar que eles estavam, implicitamente, empregando procedimentos da ciência da decisão. Dois deles, membros da Sociedade para o Estudo da Linguagem Poética (OPOIAZ), de São Petersburgo, Viktor Chklóvski e Iúri Tyniánov, consideravam o escritor um agente racional em busca de um objetivo específico e delinearam os meios disponíveis para alcançá-lo. Suas abordagens, como pretendo mostrar, correspondem assaz a dois tipos específicos de racionalidade: "racionalidade instrumental" e "racionalidade limitada". Para concluir, justaponho esses dois conceitos formalistas de poiesis à visão de Mikhail Bakhtin sobre o mesmo assunto, argumentando que a maneira como Bakhtin considera as estratégias disponíveis para o literato se ajusta aos pressupostos da "racionalidade interativa".

\section{Racionalidade Instrumental}

Muitos estudantes de Literatura Russa estão familiarizados com o estilo e com o raciocínio presentes na versão tchernitchevskiana do utilitarismo na sua crítica contundente a Notas do subsolo de Dostoiévski. Tal explicação do comportamento humano põe em correlação as preferências do indivíduo com suas ações e consequências e também iguala a racionalidade à escolha dos meios mais apropriados para alcançar os fins pretendidos. Como a estética de Chklóvski se enquadra neste perfil intelectual? Antes de seguir com minha discussão, deixe-me salientar que Chklóvski não foi a rigor um pensador, ele sempre se mostrou propenso a reconsiderar algumas de suas categorias básicas. Além disso, não está completamente

3 Metateorização é uma prática reconhecida na Sociologia, no âmbito da qual ela assume algumas funções. A que me ocorre mais facilmente é a de servir "como prelúdio à teoria do desenvolvimento". (RITZER, George. Metatheorizing in Sociology (Lexington, MA: D. C. Heath, 1991), pp. 35-50. 
claro se sua teoria do processo literário é descritiva ou prescritiva: se se trata de uma análise imparcial de sua poiesis ou de uma asserção programática que deveria ser exemplificada por meio de sua própria produção literária. Com esta ressalva em mente, retornemos a Chklóvski como um racionalista instrumental.

Que conjunto de preferências a criatividade do escritor pretende satisfazer? De acordo com as primeiras considerações de Chklóvski a este respeito, a criatividade se esforça "para devolver ao homem a sua experiência de mundo, para ressuscitar as coisas e liquidar o pessimismo."4 Isso deve ser feito, ele afirma, porque nossas forças cognitivas são embotadas pela economia da energia imposta pela inércia mental com que nós, repetidamente, contemplamos nosso entorno habitual de modo a não sermos mais capazes de perceber a realidade na sua autêntica e múltipla heterogeneidade. $O$ desafio do artista é mudar este estado de coisas indesejado por meio do ato de estranhamento, ${ }^{5}$ tomando a arte como instrumento para alcançá-lo.

Comportar-se racionalmente, no entanto, obriga o indivíduo a escolher os meios mais eficientes para alcançar o fim planejado, e, para fazer isso, ele deve dispor de um conjunto suficiente de informações sobre a natureza do seu objetivo. A práxis literária, portanto, deve ser ampliada pela poética, a disciplina que subsidia o autor com uma relação de técnicas para que o escritor faça suas escolhas; trata-se de um catálogo de procedimentos literários que permite transformar, com a máxima competência, o material extra-artístico em um texto "estranhante" e que impressiona. Esse pré-requisito explica bem o ávido interesse de Chklóvski pelo "como fazer" literário, sua busca contínua pelas mônadas da forma literária nos mais diversos domínios da arte verbal. No entanto, essa situação relativamente simples tornou-se mais complexa em 1919, quando Chklóvski mudou sua concepção a respeito do objeto

4 CHKLÓVSKI, Viktor. Voskrechenie slova, in Gamburgskii schet: Stati - vosponimania - èsse (1914-1933) (Moscou: Sovietskii pisatel', 1990), p. 40.

5 Tradução para o termo russo ostraniénie. 
do estranhamento artístico, substituindo a realidade automatizada por formas artísticas mais antigas, que perderam sua perceptibilidade devido ao uso excessivo. ${ }^{6}$

Como inicialmente previsto por Chklóvski, a melhor prática para "liquidar o pessimismo" era bastante simples. O autor, compelido pela necessidade de "estranhar" a realidade, esforça-se incessantemente por renovar os modos de percepção, dominando os procedimentos literários vitais ao seu propósito. Mas esse modus operandi precisou mudar consideravelmente depois que o autor entrou em competição com outros "causadores de estranhamento" e o estranhamento de estranhamentos prévios tornou-se seu objetivo principal. Dado os séculos em que esse processo de rejuvenescimento da morfologia literária esteve em operação, os resultados têm se tornado reduzidos, beirando a utilidade marginal. A invenção mais radical foi chamada de "a invenção do método de invenção", como Alfred Whitehead a colocou, e Chklóvski se adiantou para fornecê-la. ${ }^{7}$

A razão pela qual os autores tradicionais foram incapazes de melhorar a relação custo/benefício de seus empreendimentos decorre de suas "ingenuidades" (no sentido que Friedrich Schiller entendia este termo) -, da ausência de uma autorreflexão racional. É verdade, os textos que eles criaram visavam oferecer uma imagem contrafatual do mundo, mas os próprios autores pareciam lamentavelmente ignorar a causa subintencional de tal comportamento - qual seja, o imperativo de "estranhar". Assim, eles atribuíram falaciosamente a estranheza representacional de suas produções a motivações exógenas, quando não, a uma perspectiva não humana, ou a uma intervenção metafísica, exaurindo assim, gradualmente, a credulidade do público leitor. Os modernistas, declarava Chklóvski, devem declarar o rei nu e revelar ao público o que a arte verdadeiramente é: um amplo processo de deformação do material com vistas a produzir um efeito perceptivo específico. Seus

6 Viktor Chklóvski, "Sviaz priemov siuzhtoslozhenia s obshchimi priemami stilia, in OPOIAZ, Poètika: Sborniki po teorii poètitcheskogo iazika (Petersburgo: Z. Sokolinskii, 1919), p. 120.

7 WHITEHEAD, Alfred North. Science and the Modern World (Nova York: Macmillan, 1926), p. 141. 
escritos devem explicitar as técnicas do ofício à inspeção direta do público, apagando assim a distinção entre o material e o procedimento ou, mais precisamente, tornar os procedimentos em si o material da meta-manipulação artística.

A melhor aplicação da teoria de Chklóvski é seu romance epistolar Zoo, que fez de um procedimento literário seu protagonista. ${ }^{8}$ À primeira vista, Zoo se apresenta como um conjunto de episódios sobre a vida do famoso escritor russo vivendo ou passando pela Berlim daquele tempo com um maço de cartas íntimas trocadas entre ele e seu objeto de desejo erótico, Elsa Triolet, a qual foi inserida sem qualquer hesitação nessa miscelânea. Dada sua composição fragmentada, Zoo pode ser considerado realmente um romance? Chklóvski aborda essa questão de frente na "Carta 22", na qual apresenta, para o bem geral, uma breve história do gênero romanesco. ${ }^{9} \mathrm{~A}$ arte do romance, de acordo com suas colocações, se resume a uma concentração de histórias curtas dispersas dentro de um todo maior. Portanto, sua verdadeira história não é senão a sucessão de métodos empregados por escritores para alcançar a integração holística desejada. A figura de Dom Quixote, por exemplo, serviu a Cervantes como procedimento conveniente por reunir eventos diversos como se fossem episódios da vida do personagem; Tolstói, por sua vez, se valeu da psique de seus protagonistas mais expressivos com a mesma finalidade. Mas, à época, observou Chklóvski, a própria ideia de um fio

8 A obra de Chklóvski é um todo radicalmente descentrado que compreende três níveis: irônico, literário e político, que, implicitamente, se contradizem. Um amor não correspondido vira ensejo para inventar um romance ("não sobre o amor") que posteriormente virou um pretexto para que seu autor apelasse ao governo soviético para retornar à Rússia de seu exílio político. Zoo, entretanto, não é apenas uma ironia comum, mas uma meta-ironia, i.e, uma ironia disfarçando não ironia. Isso permite que Chklóvski finja fingir: ser a um só tempo um sujeito autoral autoconsciente (senhor de seu texto) e um objeto desafortunado dos caprichos dos outros (um pretendente descartado e um derrotado político). Neste artigo, eu foco exclusivamente no nível literário da obra de Chklóvski. Para maiores detalhes da leitura de Zoo nesta perspectiva, veja meu artigo "The Praxis of Irony: Viktor Shklovsky's Zoo", Russian Formalism: A Retrospective Glance, Robert L. Jackson e Stephen Rudy (org.), (New Haven: Yale Russian and East European Publications, 1985), pp. 27-43, ou sua versão revisada, "Praktika ironii: Zoo, ili pis'ma ne o liubvi Viktora Shklovskogo", Novoe literaturnoe obozrenie 133, 2015, pp. 169-181.

9 CHKLOVSKY, Viktor. Zoo, cartas não sobre amor [Zoo, или Письма не о любви]. Berlim: Gelikon, 1923, pp. 82-5. 
integrador tornou-se automatizada, pondo em risco destarte a sustentabilidade do próprio gênero. A resposta de Chklóvski a esse desafio histórico foi tão simples quanto ingênua: ele deixou as cartas de Zoo propositalmente embaralhadas. Foi por essa razão, porém, que Chklóvski garantiu seu público. Não apenas as cartas, como todos os blocos que integram o romance, não tinham de facto absolutamente nada em comum; mas, convenhamos que conectá-las faria de Zoo um refém do automatizado, privando o livro de qualquer potencial estranhamento. Ao colocar o procedimento vital do romance "em hesitação", ${ }^{10}$ Chklóvski acabou salvando o gênero. Levando a cabo esse procedimento, ele surgiu com um livro picante, ao chamar a atenção para um detalhe.

Se a arte verbal para Chklóvski se reduz a um puro know-how, a práxis literária não tem nada a ver com um dom exclusivo nem com uma "loucura divina", mas, ao contrário disso, ela diz respeito a um conjunto de habilidades particulares que qualquer pessoa pode alcançar desde que se disponha a dominar as regras que regem esse tipo de produção. Ao adotar tal pedagogia vocacional, Chklóvski ofereceu a escritores iniciantes dois manuais de "como fazer literatura", ambos de sua autoria. ${ }^{11} \mathrm{O}$ primeiro, publicado em 1927 com o título A técnica do ofício do escritor, era composto por quarenta e um capítulos curtos com títulos como "Escrever com precisão e com frases simples", ou "Sobre os versos e por que não é digno escrevê-los". Já o segundo, Como escrever scripts (1931), foi destinado aos habitantes da República literária e focava a crescente indústria cinematográfica soviética.

\footnotetext{
10 A expressão "under eraser", originária da filosofia de Martin Heidegger e amplamente utilizada por Jacques Derrida (sous rature), significa, conforme o Glossário de Derrida, rasura: "A rasura instaura uma economia vocabular. 0 entre aspas, o tipo gráfico da impressão, as letras riscadas e as expressões irônicas devem ser entendidas como manifestações da estratégia desconstrutora em Derrida. Usando termos de uma linguagem que quer desconstruir, Derrida abala essa linguagem e inscreve outro sentido além dela (...). Sendo a rasura uma modalidade de solicitação e estratégia, funciona como elemento regulador da polissemia e estabelece uma lógica de suplementaridade na própria sintaxe em que se inscreve. (p. 74) (N. do T.)

11 Viktor Chklóvski, Tekhnika pisatelskogo remesla (Moscou: Molodaia gvardia, 1927); Kak pisat stsenarii: Possobie dlia natchinaiuschikh stsenaristov s obraztsami stsenariev raznogo tipa (Moscou: Goslitizdat, 1931).
} 


\section{Racionalidade Limitada}

Por mais persuasiva que possa parecer, a explicação instrumentalmente racional da tomada de decisão tem perdido, nos últimos sessenta anos, seu brilho intelectual por motivos empíricos. Os indivíduos, apontaram os detratores de tal estilo de racionalidade, na verdade, não agem de acordo com fórmulas precisas. Herbert Simon, o mais influente entre os detratores, é o autor do conceito de "racionalidade limitada", que ele acreditava ser uma descrição mais apropriada de como escolhas reais são feitas do que suas contrapartidas instrumentalistas. Sua famosa metáfora compara o "comportamento racional humano" a "uma tesoura cujas lâminas são a estrutura do ambiente de tarefa e as capacidades computacionais do ator". ${ }^{12}$ São as imperfeições formativas da nossa mente que tornam essas lâminas figurativas um pouco cegas, impedindo-nos de "ampliar de maneira expressiva a utilidade esperada". Podemos não ser capazes de reunir, no tempo necessário, informação suficiente sobre o contexto de nossa ação e/ou sobre a proficiência quantitativa necessária para testar todas as variáveis. $\mathrm{E}$, além disso, mesmo que pudéssemos de alguma forma superar todos esses obstáculos, nosso bem calculado comportamento poderia ainda resultar em consequências imprevistas. Mas, apesar disso tudo, tomamos decisões de maneira racional, insiste Simon. Para os instrumentalistas, o que ocorre é que a racionalidade que empregamos é limitada e não abrangente.

Como os racionalistas limitados conduzem seus negócios? Bem pragmaticamente, eu diria. Diante de um desafio real, eles recorrem à "regra geral". Nesse sentido, chegam a uma solução que pode não ser a ideal, mas que é totalmente "satisfatória", isto é, adequada às suas necessidades práticas. Além disso, o processo de tomada de decisão é raramente uma ação simples, uma aposta aleatória em empreendimentos, como a arte, com os quais a espécie humana tem se engajado por mi-

12 SIMONS, Herbert. "Invariants of Human Behavior", Annual Review of Psychology, 1990: 41, p. 7. 
lênios. A tomada de decisão acontece dentro de um contexto cultural carregado historicamente que induz nosso comportamento, incluindo a maneira como nós fazemos escolhas. "A tradição de todas as gerações mortas", deve pesar não só "como um pesadelo no cérebro dos viventes."13 Ela também pode se mostrar como um conjunto de ferramentas úteis, "um mecanismo de comportamento frugal e rápido que dispensa os cálculos individuais de custo-benefício e a tomada de decisão."14 Dado o valor que as normas herdadas desempenham na formação de nossas expectativas, alguns estudiosos preferem acabar de uma vez por todas com o particípio do verbo "atar" na caracterização desse tipo de racionalidade, falando, em vez disso, de uma "racionalidade processual". ${ }^{15}$

Chklóvski concebia o escritor modernista como um "soberano", no sentido que Carl Schmitt conferiu a esse termo. É "ele que decide sobre a exceção"16 - a transgressão estranhante das normas literárias - sine qua non da arte verbal. Outros formalistas, contudo, objetaram vigorosamente à visão irrestrita de Chklóvski no que tange à atividade individual no processo literário. O mais proeminente entre eles foi seu amigo e membro da OPOIAZ Iúri Tyniánov. Sua perspectiva teórica, é fácil perceber, assemelha-se à dos proponentes do racionalismo limitado na medida em que, em literatura, ele insistiu, as condições externas e, sobretudo, as regras e os procedimentos herdados coletivamente fazem a escolha do autor por meios formais estéticos fracassar. Como uma instituição distributi$\mathrm{va}$, a arte verbal nasce de consequências não intencionais e o poder do indivíduo de alterá-la unilateralmente é desprezível. Claramente visando o voluntarismo de Chklóvski, Tyniánov

13 Karl Marx, The Eighteenth Brumaire of Louis Bonaparte. Nova York: International Publishers, 1963, p. 15.

14 GIGERENZER, Gerd e SELTEN, Reinhard. "Rethinking Rationality" in Bounded Rationality: The Adaptive Toolbox, org. G. Gigerenzer and R. Selten. Cambridge, MA: The MIT Press, 2001, p. 10.

15 Veja por exemplo: HEAP, Shaun Hargreaves, Rationality in Economics. Oxford: Basil Blackwell, 1989, pp. 116-121.

16 SCHMITT, Carl. Political Theology: Four Chapters on the Concept of Sovereignity, tr. George Schwab Chicago: University of Chicago Press, 2005, p. 5. 
escreveu: inovações "nascem com base em resultados 'acidentais' e em 'desvios acidentais" não de um desejo consciente. "De certo modo", ele continua, "cada defeito, cada erro, cada aberração de uma poética normativa é, potencialmente, um princípio construtivo novo." ${ }^{17}$

Mas mesmo que o autor pudesse estimar todas as consequências estéticas de sua ação, adaptando favoravelmente a morfologia de sua obra em função do efeito desejado, o projeto ainda sofreria interferências. Aqui reside a segunda diferença entre Chklóvski e Tyniánov. Para o primeiro, a literatura era um campo autônomo governado pelo algoritmo inteiramente endógeno do estranhamento, o qual, Chklóvski parecia acreditar, pode ser totalmente controlado. Para o segundo, o campo literário a priori estava sempre inserido na esfera mais ampla da cultura em geral - "um sistema de sistemas", no seu linguajar. ${ }^{18}$ Tal totalidade cultural segue sua própria regularidade estrutural exógena à literatura e impacta seu desenvolvimento imanente, o qual, desnecessário dizer, injeta uma boa dose de aproximação a qualquer tomada de decisão literária. Ou seja: a transição do Classicismo para o Sentimentalismo nas letras russas por volta da virada do século XVIII - ao olhar desatento um fato puramente literário - estava, de fato, conforme Tyniánov mostrou, intrinsicamente atrelada à mudança geral no ambiente comunicativo dominante na sociedade russa de então. A substituição da corte refinada e formal pelo salão particular e descontraído que cultivava a arte da conversação refinada foi claramente uma transformação que nada teve a ver com as convenções literária per se, mas, não obstante, as modificou significativamente. ${ }^{19}$

Qual é, de acordo com Tyniánov, o objetivo de um literato? Sua resposta a essa pergunta é uma nuançada versão do estranhamento chklovskiano. De acordo com Tyniánov, o escritor deseja realizar uma "construção discursiva dinâmica", isto é,

17 TYNIÁNOV, lúri. "Literaturnii fakt", Poètika. Istoria literatury. Kino. Moscou: Nauka, 1977, p. 263.

18 JAKOBSON, Roman e TYNIÁNOV, lúri. "Problemas dos estudos literarários e linguísticos". [ПРОБЛЕМЫ ИЗУЧЕНИЯ ЛИТЕРАТУРЫ И ЯЗЫКА] ibid., р. 283.

19 TYNIÁNOV, lúri. “Sobre a evolução literária”. ibid., p. 279. 
um ato enunciativo no qual o leitor perceba a disputa pela dominação e subordinação entre os componentes textuais (sonoridade versus sentido na poesia, por exemplo). ${ }^{20} \mathrm{E}$, como é esperado, é apenas uma questão de tempo até que este efeito precioso ocorra. As duas fontes principais de incertezas sob as quais os artistas devem tomar suas decisões morfológicas foram mencionadas acima. A última marca de nível do sucesso - o aferidor que mensura o grau de novidade - é o conjunto de procedimentos interpessoais sobre os quais os artistas não têm controle. Além disso, essas regras e regulamentos são um alvo em movimento não só porque estranhamentos efetivos estão constantemente impactando tais regras, mas também porque alterações culturais podem, a qualquer momento, cancelar a validade dessas regras. Dada essa fluidez, podem os artistas agir de maneira totalmente racional?

Podem, de acordo com Tyniánov; mas de uma maneira limitada, por meio de uma estimativa regulável. Estudando as estratégias de autores que, contra todas as probabilidades, conseguiram influenciar a tradição, Tyniánov apresentou a técnica fluida da paródia como a melhor aposta. Isso ocorre porque a estrutura da obra literária é uma delicada oscilação entre dois extremos. Para ser reconhecida como literatura, a obra deve ser iterativa, regurgitar fórmulas poéticas verdadeiras e testadas. Mas, ao fazê-lo, ela não pode simplesmente ser réplica de outras obras. $\mathrm{O}$ epigonismo, aos olhos dos formalistas, mata a arte. Ao mesmo tempo, porém, a novidade não deve ser radical ao ponto de despojar o texto, por uma questão de originalidade, de todos os seus atributos literários. Uma boa dose, ad hoc, de redundância e entropia por meio da paródia combinaria bem, na opinião de Tyniánov, com este duplo desafio. Os parodistas se prendem a sistemas de normas literárias por meio de um texto que já pertence à tradição só para "extraí-lo do sistema literário... [e] para desmembrá-lo como um sistema." ${ }^{21}$ Após ser dissolvido em suas partes constituintes, o texto parodiado é recombinado com novos elementos,

20 TYNIÁNOV, lứri, "O fato literário" ibid., p. 261.

21 TYNIÁNOV, lúri . "Sobre a paródia", ibid., p. 292. 
claramente incongruentes entre si, substituindo alguns desses elementos originais. As paródias juvenis que Nekrássov fez dos poemas românticos de Lermontov ilustram bem esta técnica híbrida. Elas misturam "figuras rítmico-sintáticas elevadas" retiradas da obra do venerável escritor com dissonante "vocabulário e temas baixos". Além disso, embora bastante marginal em sua obra, as paródias de Nekrássov, na visão de Tyniánov, preparam o terreno para o tipo prosaico da poesia cívica russa nos anos de $1950 .{ }^{22}$

\section{Racionalidade interativa}

Mikhail Bakhtin, o último assunto a ser considerado, é uma figura notadamente difícil de abordar por mais de uma razão, a mais preponderante entre elas é a natureza inconstante do seu pensamento, a vontade de revisitar seus conceitos estabelecidos e reinterpretá-los de uma perspectiva verdadeiramente nova. Aventurar-se na apresentação de seu entendimento da produção literária de uma maneira exaustiva exigiria infinitamente mais espaço do que disponho aqui. Por essa razão, focarei apenas em uma parte de seu mais antigo ensaio dos anos de 1920, convenientemente recolhido no primeiro volume de seus Collected Works, cuja "arquitetônica" (um dos termos favoritos de Bakhtin) é relativamente coerente e me fornece material suficiente para estabelecer um quadro de restrições e escolhas com os quais um escritor criativo se depara, de acordo com o jovem Bakhtin, quando se incumbe de fazer literatura.

Se o duo da OPOIAZ Chklóvski e Tyniánov, apesar da marcante discrepância em relação aos tipos de racionalidade a que eles pertencem individualmente, consideravam-se companheiros de viagem, Bakhtin pertencia a uma tendência acadêmica totalmente diferente, hostil à OPOIAZ. Desde o início de sua carreira, ele criticou vigorosamente a Escola Formal. Ao classificar as numerosas objeções que ele fez, basta dizer que Bakhtin considerava a sua abordagem da obra literária

22 TYNIÁNOV, lúri. "Stikhovye formy Nekrasova", ibid., pp. 18-27. 
superior à dos formalistas devido à sua natureza sintética. A diferença fundamental entre ele e os formalistas, dizia ele, é que sua estética baseada na filosofia procurava estabelecer o que todas as artes têm em comum e como elas interage com a totalidade da cultura em geral; enquanto os formalistas partiam de uma abordagem estritamente previsível de uma única arte (literatura), postulando sua autonomia. Eles privilegiaram o que separa a literatura de todas as demais artes, isto é, seu material. E, inspirados nas ciências naturais - acusou Bakhtin -, os críticos formalistas reduziam a literatura à sua fisicalidade ôntica, deixando fora de seu campo de interesse significados e valores que inelutavelmente conectam a arte à vida. Foi precisamente o recurso da racionalidade interativa, como mostrarei à frente, que possibilitou a Bakhtin superar a cisão entre esses dois domínios.

Então, qual era o propósito da literatura para Bakhtin? Estranhamente, ele não abordou diretamente essa questão. Parece justo supor, porém, que ele concebia a arte da palavra como uma implementação da máxima do oráculo da Ilha de Delfos, popularizada por Sócrates: "Conhece-te a ti mesmo!". Isso por si só já soaria bastante prosaico se não fosse pela conceituação incomum que Bakhtin atribui a essa ideia. Conhecer a si mesmo, ele defendia, é como dançar tango: deve ser sempre a dois. Prima facie, este postulado parece bastante contraintuitivo e precisa ser deslindado. No entanto, essa concepção tem papel fundamental na teoria bakhtiniana da arte. "Um evento estético", ele insiste, "pode se concretizar apenas na presença de dois participantes." Ele pressupõe duas consciências não idênticas. Se essa condição não for atendida, por qualquer motivo, estamos diante de eventos que podem ser extraestéticos, éticos, cognitivos ou religiosos. "A este respeito", ele continua, em outra passagem, "podemos falar da necessidade estética absoluta de um ser humano por outro, para se ver, relembrar, juntar e unificar a atividade do outro, capaz de produzir uma personalidade aparentemente acabada do ser. Essa personalidade poderia não existir até que o outro a crie." ${ }^{23}$

23 "0 autor e a personagem" [Avtor i gueroi v estetitcheskoi deiatelnosti], Sobranie sochinenii, vol. 1: Filosofskaia èstetika 1920-ch godov. Moscou: Izdatelstvo Russkie slovari, 2003, 
A palavra-chave na citação acima sobre o ponto de vista de Bakhtin a respeito da autocognição é o vocábulo "acabado". Seres humanos isolados, o pensador [мыслитель] russo nunca cansou de repetir, são, a priori, incapazes de construir uma imagem acabada ou "consumada" (outra palavra predileta de Bakhtin) de si mesmos, mas apenas algo parcial, fragmentos incompletos, cada um possuindo seu próprio percurso separado. Por quê? Porque cada perspectiva individual é, por definição, limitada tanto temporalmente quanto espacialmente. Videlicet: os dois momentos definidores de minha existência - o nascimento e a morte - estendem-se para além dos limites da minha cognição, da mesma forma que sou incapaz de examinar diretamente certas partes do meu corpo. Dessa for$\mathrm{ma}$, o "autoconhecimento propiciado pela terceira pessoa" 24 é uma obrigação. Somente uma pessoa externa - alguém localizado fora de um determinado espaço circunscrito, fora do ponto subjetivo ocupado por mim e, dessa forma, no comando de dados excedentes a meu respeito - é capaz de apreender a minha existência na sua totalidade, como um evento completo e acabado. É precisamente a arte, Bakhtin insiste, que melhor se adequada em fornecer uma imagem totalizante do ser, fornecendo-lhe o sentido e o valor que seus fragmentos díspares e contingentes em si mesmos não possuem.

O caso paradigmático que Bakhtin chama de uma interação "respondível" ${ }^{25}$ entre dois seres - a autorrealização refletida de um por meio do outro - é a relação entre o autor e seu personagem. "Sem a personagem" - ele sustenta - "não há, via de regra, visão estética [ou] obra artística" e o que importa é

pp. 102 e 115.

24 Para uma discussão deste conceito veja por exemplo PEDRINI, Patrizia e KIRSCH, Julie. (org.). Third Person Self-Knowledge, Self-Interpretation, and Narrative. Cham: Springer, 2018, ou CHOIFER, Alla. "A New Understanding of the First-Person and Third-Person Perspectives", Philosophical Papers 2018: 47, no. 3, pp. 333-371.

25 Optou-se aqui pela utilização dos termos "respondível" e "respondibilidade" que correspondem ao termo russo "ответственность", utilizado no original por Bakhtin. Peter Steiner utiliza a expressão "answerability", já consagrada entre os bakhtinianos norte-americanos, para traduzir o termo russo. No Brasil essa palavra muitas vezes foi traduzida como "responsabilidade", o que amplia demasiadamente o campo semântico do termo no original russo. (N. do T.) 
apenas seu tipo: "real, expresso [ou] potencial" ${ }^{26}$ Externo ao personagem e, dessa forma, numa posição que lhe permita conhecer mais sobre o personagem do que sobre si mesmo, o escritor tem a possibilidade de completar a imagem do sujeito representado, dando, desta maneira, objetividade e ordem ao rol de características contingentes. No entanto, e isso deve ser enfatizado, "uma imagem estável e circunscrita de um personagem" não é algo dado antes do seu vir a ser, trata-se de um ideal a ser realizado por meio do "embate do artista... com ele mesmo" ${ }^{27} \mathrm{~A}$ fonte de seu conflito interno é o fato de que a consumação da forma estética não é um tiro certeiro, mas, antes disso, um disparo que oscila entre duas atitudes mutuamente dissonantes, quais sejam: empatia e distanciamento. "Para estar engajado esteticamente", escreve Bakhtin,

Devo me projetar em outro ser, ver seu mundo axiologicamente de dentro, como ele mesmo vê esse mundo, assumir sua posição, e então, após retornar ao meu próprio locus de origem, preencher seu horizonte com o excedente de visão que o meu próprio horizonte externo a ele fornece. Devo circunscrevê-lo, criar um ambiente consumado para ele fora dos excessos da minha própria visão, do meu conhecimento, do meu desejo e dos meus sentimentos. ${ }^{28}$

$\mathrm{Ou}$, de uma maneira menos prolixa, "a consciência autoral é a consciência de uma consciência"; em suma: o autor "não deve falar de sua vida, mas falar sobre sua vida pelos lábios do outro." $^{29}$

Neste ponto, leitores exigentes podem suspeitar da minha linha de pensamento. E isso seria justo! Eu não comecei, eles poderiam asseverar, chamando a estética de Bakhtin de interativa? No entanto, lamentavelmente, até este momento minha apresentação das ideias do pensador russo focou unicamente na consciência isolada com o "significante" outro como uma mera invenção dessa imaginação artística. Para desviar essa posição ameaçadora, devo pontuar que a relação autor/

26 Ibid., p. 86.

27 Ibid., p. 90.

28 Ibid., p. 106.

29 Ibid., p. 106. 
personagem, em que "a existência total do outro é vista de fora: não apenas seu próprio conhecimento de que está sendo percebido pelo outro, mas também para além de sua consciência de que tal outro de fato existe", ${ }^{30}$ é, para Bakhtin, apenas o caso mais incipiente de nossa autorrealização através do outro. Essa situação unilateral existe apenas na arte. E, devido à passividade do personagem, ela pode servir aqui como o instrumento de um jogo livre sem fim. No entanto - e isso é um sinal -, um procedimento mental idêntico a esse opera em todas as modalidades de interação humana. A capacidade "de tornar autor" um outro, para renovar a linguagem de Bakhtin, corresponde estritamente ao que a psicologia cognitiva moderna chama, de maneira um tanto infeliz, de "Teoria da mente" - "nossa capacidade cotidiana de 'entrar na cabeça' das pessoas e contemplar o que elas desejam, sabem, pretendem e acreditam" -, cuja habilidade nos separa daqueles que não a possuem: os autistas, esquizofrênicos e outros indivíduos com problemas semelhantes. ${ }^{31}$ Se não fôssemos capazes de "ler pensamentos", de incutir nos outros motivos, crenças ou violações assumidos, enquanto recursivamente preparamos as estratégias preventivas para responder a elas, as interações humanas se transformariam numa série de coalisões caóticas sem qualquer sentido.

Para ilustrar minha afirmação, deixe-me comparar a concepção bakhtiniana de uma interação "respondível" em literatura com a tão falada "teoria da simulação" - a tese amplamente aceita sobre como atribuímos pensamentos aos outros na vida cotidiana -, pertencente à supracitada "teoria da mente". "Em primeiro lugar", argumenta seu defensor, Alvin Goldman, "o atribuidor cria nele mesmo estados falsos com vistas a alcançar seu objetivo. Em outras palavras, o atribuidor tenta se enquadrar nos 'padrões mentais' de seu alvo... O segundo passo é alimentar esses estados falsos com algum mecanismo da própria psicologia do atribuidor - por exemplo, uma toma-

30 HOLQUIST, Michael. Dialogism: Bakhtin and His World, 2a edição. Londres: Routledge, 2002, pp. 32-3.

31 APPERLY, lan. Mindreaders: The Cognitive Basis of "Theory of Mind. Hove: Psychology Press, 2011, p. 1. 
da de decisão ou um mecanismo de geração de emoção - e permitir que esse mecanismo opere sobre os estados de simulação para gerar um ou mais estados novos... Em terceiro lugar, o atribuidor atribui o resultado ao seu alvo como um estado que o alvo experimentará (ou já tenha experimentado)." ${ }^{32}$ Enquanto os dois primeiros estados reais de "leitura de mente" correspondem muito diretamente ao processo dual bakhtiniano de empatia/distanciamento entre autor e personagem, a poiesis, como ele entende esse termo, dispensa a última etapa porque as personagens da literatura são meros avatares, representações de interlocutores, e não pessoas reais.

Eu poderia ter afastado a suspeita de que a abordagem bakhtiniana da obra literária não pode ser considerada interativa. Mas há outro obstáculo na minha abordagem que parece ainda mais prejudicial à minha hipótese. Dada a ávida aversão de Bakhtin ao racionalismo de sua época, estaria justificada minha ação de chamar tal interatividade de racional? "Toda filosofia contemporânea brotou do racionalismo", ele criticou de maneira enérgica, "e está inteiramente saturada do preconceito do racionalismo que afirma que só a lógica é clara e racional." ${ }^{\prime 33} \mathrm{O}$ infortúnio de tal sagacidade - Bakhtin se detém sobre essa ideia algumas páginas adiante - vem daquilo que Karl Popper denominou "a doutrina da primazia da repetição lógica", que "fornece um tipo de justificativa para a aceitação de uma lei universal", ${ }^{34}$ a saber, que "a verdade ... é composta de momentos universais; que a verdade de uma situação é precisamente o que é repetível e constante nela, [e apenas] o que é universal e idêntico importa (logicamente idêntico)" ${ }^{35}$

32 GOLDMAN, Alvin I. "Imitation, Mind Reading, and Simulation," Perspectives on Imitation: From Neuroscience to Social Science, vol. 1, HURLEY, Susan e CHATER, Nick (org.). Cambridge, MA: MIT Press, 2005, pp. 81-82

33 "K filosofii postupka", Sobranie sotchinienii, p. 30.

34 POPPER, Karl. The Logic of Scientific Discovery (London: Taylor and Francis e-Library, 2005), p. 440.

35 "K filosofii postupka", p. 30.0 melhor exemplo de tal abordagem completamente formalizada à interdependência mútua de indivíduos no processo de tomada de decisão é a teoria dos jogos, que desde a publicação do importante Theory of Games and Economic Behavior, de John von Neumann e Oskar Morgenstern (Princeton: Princeton University Press, 1944), tem emergido da matemática como uma matriz interdisciplinar abrangente através de uma 
Um ato estético verdadeiro, como Bakhtin o concebia - a interação respondível entre duas mentes contrárias, cada uma com suas respectivas bagagens de emoções, de histórias, de desejos pessoais (a lista poderia ser mais longa) - realizáveis de diversas maneiras -, é um evento singular e inerentemente irrepetível, uma exceção a qualquer regularidade. Mas essa circunstância, aos olhos de Bakhtin, não a torna irracional, para ser sincero. "De fato, o ato performático em sua totalidade", afirma ele, "é mais que racional - ele é respondível" "Racionalidade é, portanto, um momento de respondibiliade." ${ }^{36}$

O verdadeiro desafio da crítica de Bakhtin, conforme as citações acima parecem sugerir, não é o racionalismo per se, mas apenas um certo tipo de racionalismo: sua redutível variante lógico-matemática ideal para situações abstratas de tomada de decisão com uma solução única. No entanto, um tanto quanto curioso, ele não rejeita a racionalidade, mas a inclui sob o abrangente termo guarda-chuva "respondibilidade", como se fosse uma de suas manifestações. Essa categoria em si, apesar da extrema singularidade de todos os atos que a compõem, em vez de ser irracional é, para Bakhtin, o epítome de uma forma diferente/mais elevada de racionalidade. Que tipo de racionalidade é, então, a respondibilidade? Obviamente, não se trata de um infalível mathesis universalis, de um nostrum autorredentor contra uma falibilidade demasiado humana, mas sim algo completamente diferente disso: ela é uma inteligência social amplamente concebida, uma bússola rústica que nos ajuda a navegar nossas trajetórias através de um universo de relações transpessoais opacas, que se mostram multifacetadas, multiníveis e multifatoriais. Esse entendimento da racionalidade interativa, eu acrescentaria, está em voga hoje em dia entre alguns cientistas do desenvolvimento cognitivo. Deixe-me explicar.

matriz crescente da ciência social. Para uma pesquisa útil de um balanço transdisciplinar da teoria dos jogos veja, por exemplo, PIETARINEN, Ahti-Veikko. "Games as Formal Tools versus Games as Explanations in Logic and Science", Foundations of Science 8: 2003, pp. 317-63.

36 Ibid., p. 36. 
O enigma da razão, Hugo Mercier e Dan Sperber explicam, em um livro de mesmo nome, é algo dúbio. Se a razão é uma faculdade cognitiva eminentemente útil que colocou o homo sapiens no topo do polo totêmico evolucionário, então indaga-se: por que ela não se desenvolveu em um nível comparável com o de outras espécies? Além disso, se a razão tem sido um componente da mente humana por tanto tempo, por que ela não se desenvolveu com o tempo, permanecendo tendenciosa, ilógica e sistematicamente falha? ${ }^{37}$ Uma vantagem real do desenvolvimento dos humanos em relação aos outros seres, e eis aqui a resposta à primeira indagação, é a sua cooperação intensiva sustentada pela vasta e complexa rede de conexões intersubjetivas e recíprocas. A razão - "uma adaptação ao nicho hipersocial que os humanos têm construído para si mesmos" - seria, como uma ferramenta organizacional para gerenciar a sua delicada coexistência, totalmente sem utilidade para espécies que são muito menos socializadas que nós. ${ }^{38}$ No que se refere à segunda pergunta, que, de um ponto de vista estritamente lógico, parece que "o viés da razão e a preguiça não são falhos," nossos autores observam, "elas são recursos que ajudam a razão a cumprir sua função [social]... a encontrar razões que sustentem [o seu] ponto de vista" e/ou que validam sua posição. ${ }^{39}$

Isso não significa, de modo algum, e a dupla de cientistas cognitivos se apressam em afirmá-lo (ofuscando o pensamento de Bakhtin), que a racionalidade social não tem utilidade para a lógica como um todo. Ao contrário da doxa comum, seu papel não é nos conduzir a soluções intrinsicamente melhores. Para que ela serve, então? Na primeira parte deste artigo,

37 MERCIER, Hugo e SPERBER, Dan. The Enigma of Reason (Cambridge, MA: Harvard University Press, 2017), p. 4.

38 Ibid., p. 330.

39 Ibid., p. 331. "As pessoas são tendenciosas ao buscar razões que amparem seus pontos de vista porque assim é como elas podem justificar ações e convencer os outros a compartilhar suas crenças. Você não pode justificar a si mesmo pressentindo reações que enfraqueçam sua justificativa... E se as pessoas raciocinam preguiçosamente, é porque, numa interação padrão, essa é a maneira mais eficiente a proceder. Ao invés de trabalhar duro para antecipar contra-argumentos, geralmente é mais eficiente esperar que seus interlocutores os forneçam." Ibid. 
que dispõe sobre a racionalidade limitada, comentei suficientemente sobre a imprecisão do processo de tomada de decisão em situações reais. Mercier e Spencer apenas ampliam, de uma perspectiva diferente, este achado crítico. De acordo com eles, nossa escolha de uma alternativa fixa entre todas as plausíveis está fadada a fracassar porque ela se baseia sobretudo nos "procedimentos da inferência intuitiva", a qual eles julgam inconsciente, oportunista e diversa." ${ }^{40}$ No fundo, essa tacanhez não deve nos irritar. A falha de fato ocorre apenas quando precisamos comercializar nossa inábil escolha na ágora (praça pública), justificando-a e convencendo os outros a comprá-la. Mas, para esse propósito, a lógica se torna bastante útil: não apenas como uma norma absoluta ou como um método compreensivo, mas como um instrumento auxiliar de esclarecimento. "No raciocínio argumentativo em particular", aprendemos com a leitura de $O$ enigma da razão, "o uso da relação lógica desempenha um papel heurístico no nosso público. A relação lógica ajuda a desafiar as pessoas a examinar e enriquecer ou revisar suas crenças, ou então a defendê-las com argumentos. Graças em parte à sua roupagem lógica, a argumentação, embora nem sempre convincente, é ao menos geralmente desafiadora." ${ }^{41}$

Depois desta longa e necessária digressão, deixe-me recapitular rapidamente os princípios básicos da estética de Bakhtin e tirar dela algumas conclusões da perspectiva da ciência da decisão. A utilidade da arte decorre, de acordo com o pensador russo, da capacidade que ela tem de efetuar um processo específico de autognose humana. Para ser produtivo, o aprendizado sobre si mesmo requer uma reduplicação não-idêntica da consciência do autor, a criação de uma personagem que o autor - através de um movimento duplo de identificação e distanciamento dessa estância fictícia - enquadra, adquirindo no processo informações novas sobre o próprio autor. Completamente ciente da impressionante complexidade axiológica que subjaz a todas as formas de interação humana e da variedade

40 Ibid., p. 173

41 Ibid., p. 168. 
de formas que ela pode assumir, não obstante sua dimensão afetiva/aspiracional, Bakhtin, ao contrário dos Formalistas, resiste em formular qualquer poética sistemática, não há um inventário dos meios à disposição do autor para tornar sua relação respondível com o personagem artisticamente mais eficiente. Para alcançar esse fim, os praticantes da arte da palavra devem confiar apenas em seu domínio das habilidades interpessoais - em sua racionalidade interativa. ${ }^{42}$

No entanto, há uma preferência estética de Bakhtin com a qual os Formalistas podem concordar. Ela diz respeito ao grau de estranhamento da personagem em relação ao seu criador: quanto menos familiar, melhor. Bakhtin fica muito menos entusiasmado a respeito, diga-se, da poesia lírica, na qual a distância entre os dois (autor e personagem) parece mínima e "a consumação formal [da personagem] é alcançada com certa facilidade", ${ }^{33}$ do que a respeito de qualquer outro tipo de prosa (mesmo a autobiográfica), que, a este respeito, sempre se apresenta muito mais polarizada. Isso, no entanto, já era de se esperar, devido ao "conheça-te a ti mesmo" da utilidade da arte. $O$ contato com alguém totalmente estranho tem um potencial muito maior de nos falar sobre nossas próprias cegueiras do que uma interação automatizada com alguém que vemos diariamente.

\footnotetext{
42 A desconfiança de Bakhtin em relação a qualquer poética sistemática anda de mãos dadas com sua posição antiformalista, negando à arte verbal qualquer autonomia vis-à-vis outros domínios culturais e, em vez disso, concebe-a como um exercício a posteriori. "A atividade estética não cria uma nova realidade. Em contraste com a cognição e com a [ética] ação, que produzem a natureza e a humanidade social", Bakhtin declara. Ele continua: "a arte cria uma nova forma como uma nova relação axiológica em direção ao que já tem se tornado realidade pela cognição e pela ação". ("Poblema formy, soderjánia i materiála v slovesnom khudojestvennom tvortchestve," Sobranie sotchinenii, vol. 1, p. 287). Dessa perspectiva, pode ser reinvindicado, o personagem é uma personificação de um conjunto de valores e ideias disjuntivas e de atitudes que o autor criativamente refrata ao enclausurá-las dentro de uma forma artística.
} 


\section{Inventário epistemológico}

Para concluir, deixe-me destacar as diferenças entre três estudiosos de literatura por meio do mapeamento de suas teorias num quadro epistemológico amplo, empregando para tal os insights de Ernest Gellner sobre o assunto. "Há duas teorias fundamentais do conhecimento", afirmou o filósofo tcheco-britânico, "que permanecem em forte contraste uma com a outra. Elas são profundamente opostas." ${ }^{44}$ Essas duas epistemologias mutuamente irreconciliáveis são a concepção individualista/atomística - na esfera do Iluminismo - e a coletivista/orgânica, que nasceu com o Romantismo. De acordo com a primeira, a cognição é um processo empírico em que um indivíduo isolado agrega quantias distintas de informação externa em um todo racional, enquanto interesses privados, livres de quaisquer convenções, guiam suas ações. De acordo com a última, somos partes integrantes de um todo cultural. O que importa é a trama social envolvendo a todos e não os integrantes desse complexo em si mesmos. Quem somos e o que pensamos é uma função dessas representações mentais coletivas - que desconhecem autoria e propriedade - sobre as quais podemos fazer muito pouco. Não é preciso ser um especialista para reconhecer Chklóvski, o racionalista instrumental, como o herdeiro do paradigma individualista, e a racionalidade limitada/processual de Tyniánov como uma encarnação particular do conceito coletivista de conhecimento.

A abordagem interativa de Bakhtin, eu gostaria de propor, oferece uma passagem entre Cila e Caríbdis a esses dois paradigmas incompatíveis. Seu conceito-chave - a respondibilidade - age no sentido de lançar uma luz diferente sobre como as pessoas agem. A noção de respondibilidade resgata o conceito do indivíduo condenado à morte pela coletividade, ao mesmo tempo sem incorrer nos extremos do individualismo de Robinson Crusoe propagado pelos atomistas. Desse ponto de vista particular, podemos ser indivíduos autônomos agindo por

44 GELLNER, Ernest. Language and Solitude: Wittgenstein, Malinowski and the Habsburg Dilemma. Cambridge: Cambridge University Press, 1998, p. 3. 
interesses próprios, mas não necessariamente mônadas sem janelas, desconectadas do meio social. Isso ocorre, Bakhtin argumenta, porque a natureza humana é, antes de mais nada, interativa: nossa individualidade não pode ser constituída integralmente sem a mediação do outro. Nosso comportamento poderia ser egoísta, mas, na medida em que ele deve refletir a paisagem mental daqueles com quem nos envolvemos, nossa tomada de decisão não pode ser totalmente autoconfinada. Ela deve, nolens-volens, transcender os limites de uma consciência única, deve levar em conta o outro, invadir a mente e imaginar suas ações à luz de nossas ações, enquanto prefigura nossas próprias respostas subsequentes. Somente no interior dessa trama recursiva e desdobrante, exercível na arte com o mais alto grau de liberdade, podemos descobrir esses aspectos da nossa existência que, do contrário, permaneceriam para sempre ocultos a nós mesmos.

À primeira vista, e estou pronto a assumir a culpa, esse esquema pode ser visto como grandioso. No entanto, ele não é de todo desprezível se para tanto o relacionarmos com a sensibilidade artística e com as inclinações teóricas da tríade em consideração. A fixação de Chklóvski pela literatura do século XVIII e pela cultura em geral é bem conhecida ${ }^{45}$ Como crítico, ele analisou o estilo de Laurence Sterne e o assimilou em sua própria práxis literária, chegando até mesmo a se apropriar do título de um de seus romances, Viagem Sentimental, para dar nome às suas memórias dos anos tumultuados de 1917-1922.46 Ele também prestou reverência a Jean-Jacques Rousseau não apenas ao empregar em seu Zoo o gênero epistolar tão característico do romance mais famoso desse autor, mas também por marcar esta filiação através do segundo subtítulo: $A$ Terceira Heloísa.

45 Chklóvski permaneceu temporalmente sintonizado com... a linha de frente da sátira do século XVIII", escreve Caryl Emerson, e "atraído pelos valores iluministas do século XVIII, que insistiam na subordinação do material existente à mente" ("Shklovsky's ostranenie, Bakhtin's vnenakhodimost': How Distance Serves an Aesthetics of Arousal Differently from an Aesthetics Based on Pain", Poetics Today, 26:4, pp. 639 e 647.

46 Laurence Sterne, A Sentimental Journey through France and Italy: By Mr. Yorick (London: T. Becketand P. A. De Hondt, 1768); Viktor Shklovsky, Sentimentalnoe putechestvie: Vospominania 1917-1922 (Berlim: Guelikon, 1923). 
A poética intersubjetiva e holística de Tyniánov remete reconhecidamente à ambiência intelectual do período com o qual este esteve mais diretamente envolvido: a primeira metade do século XIX. Dentre os Formalistas, ele foi o primeiro romancista cuja pesquisa mudou de maneira substancial nosso entendimento desse período da Literatura Russa. Depois de trocar o ofício de crítico pelo de escritor criativo no final da década de 1920, Tyniánov empregou seu vasto conhecimento histórico do século XIX para compor suas ambientações romanescas, permeadas de detalhes surpreendentes, de vários poetas românticos russos: o menos conhecido Wilhelm Küchelbecker ou Aleksander Púchkin que, como um dos seus biógrafos observou, "foi para Tyniánov o homem mais importante da história russa". Mesmo hoje, quase um século depois, as traduções de Tyniánov para o russo de obras de Heinrich Heine são ainda apreciadas por seus compatriotas.

O escritor que fascinou o jovem Bakhtin e que foi o objeto de sua primeira monografia acadêmica foi Fiódor Dostoiévski - o escritor que abordou incansavelmente a questão do individualismo. "O enigma fundacional da escrita de Dostoiévski", observou um comentador recentemente, "talvez o aspecto mais confuso, contraditório e agonizante de sua visão de mundo filosófica", seja a "sua, a um só tempo, defesa e rejeição do self." No início do meu ensaio, mencionei brevemente a crítica do racionalismo instrumental de Dostoiévski - o pivô intelectual do individualismo burguês ocidental que ele abominou. Uma busca obstinada por uma altruísta desindividualização anima muitos de seus melhores romances. Isso, entretanto, não significa que Dostoiévski abraçou a dissolução romântica do ego na coletividade anônima. Em vez de negar a categoria de individualidade, ele preferiu destacá-la: postular um self que fosse as duas coisas ao mesmo tempo: integral no seu próprio direito, mas integrado com o outro. "Na mesma passagem em que [Dostoiévski] defende a aniquilação do 'eu', o comentador acima mencionado sintetiza: "ele defende veementemente a necessidade de "tornar-se uma personalidade", num nível muito mais elevado do que o que tem sido definido atualmente no Ocidente. Sobre se Dostoiévski conseguiu essa sua bus- 
ca zetética de tal personalidade, permanecerei calado. Mas, mesmo que ele tenha falhado, a noção de respondibilidade de Bakhtin ofereceu uma elaboração estimulante da aporia que tanto preocupou seu autor favorito.

\section{Referências bibliográficas}

APPERLY, Ian. Mindreaders: The Cognitive Basis of "Theory of Mind". Hove: Psychology Press.

BAKHTIN, Mikhail. "Avtor i gueroi v estetitcheskoi deiatelnosti" ["O autor e a personagem na atividade estética"], Sobranie sotchinenii, vol. 1: Filossofskaia estetika 1920-kh godov. Moscou: Izdatelstvo Russkie slovari, 2003.

CHOIFER, Alla. "A New Understanding of the First-Person and Third-Person Perspectives," Philosophical Papers, 2018.

CHKLÓVSKI, Viktor. "Sviaz priemov siujetoslojenia s obshchimi priemami stilia", in OPOIAZ, Poetika: Sborniki po teorii poetitcheskogo iazika, S. Petersburgo: Z. Sokolinskii, 1919.

CHKLÓVSKI, Viktor. "Voskrechenie slova" ["Ressurreição da palavra"], in Gamburgskii schet: Stati - vosponimania - esse (1914-1933). Moscou: Sovietski pissatel, 1990.

CHKLÓVSKI, Viktor. Zoo, ili Pisma ne o liubvi [Zoo, ou cartas não sobre amor]. Berlim: Guelikon, 1923.

GELLNER, Ernest. Language and Solitude: Wittgenstein, Malinowski and the Habsburg Dilemma. Cambridge: Cambridge University Press, 1998.

GIGERENZER, Gerd e SELTEN, Reinhard. "Rethinking Rationality" in Bounded Rationality: The Adaptive Toolbox, org. G. Gigerenzer and R. Selten. Cambridge: The MIT Press, 2001.

GOLDMAN, Alvin I. "Imitation, Mind Reading, and Simulation", Perspectives on Imitation: From Neuroscience to Social Science, vol. 1, HURLEY, Susan e CHATER, Nick (org.). Cambridge: MIT Press, 2005.

HEAP, Shaun Hargreaves, Rationality in Economics. Oxford: Basil Blackwell, 1989.

HOLQUIST, Michael. Dialogism: Bakhtin and His World, 2a ed. 
Londres: Routledge, 2002.

JAKOBSON, Roman e TYNIÁNOV, Iúri. "Problemy Izutcheniia Literatury i Iazika ("Problemas dos estudos literários e linguísticos"), ibid.

MARX, Karl. The Eighteenth Brumaire of Louis Napoleon. Nova York: International Publishers, 1963.

MERCIER, Hugo e SPERBER, Dan. The Enigma of Reason. Cambridge: Harvard University Press, 2017.

NORTH, Warner D. "A Tutorial Introduction to Decision Theory", IEEE Transactions on Systems Science and Cybernetics, vol. SSC-4, no. 3; setembro, 1968.

WHITEHEAD, Alfred North. Science and the Modern World. Nova York: Macmillan, 1926.

PEDRINI, Patrizia e KIRSCH, Julie. (org.). Third Person Self-Knowledge, Self-Interpretation, and Narrative. Cham: Springer, 2018.POPPER, Karl. The Logic of Scientific Discovery. Londres: Taylor and Francis e-Library, 2005.

RITZER, George. Metatheorizing in Sociology. Lexington: D. C. Heath, 1991.

SCHMITT, Carl. Political Theology: Four Chapters on the Concept of Sovereignty. Trad. George Schwab. Chicago: University of Chicago Press, 2005.

STERNE, Laurence. A Sentimental Journey through France and Italy: By Mr. Yorick (London: T. Becketand P. A. De Hondt, 1768); Viktor Shklovsky, Sentimentalnoe putechestvie: Vospominania. 1917-1922. Berlim: Guelikon, 1923.

TYNIÁNOV, Iúri. "Literaturnyi fakt", Poetika. Istoria literatury. Kino. Moscou: Naúka, 1977.

WHITEHEAD, Alfred, SIMONS, Herbert. "Invariants of Human Behavior", Annual Review of Psychology, 1990.

Tradução de Valteir Vaz

Recebido em: 15/07/2020

Aceito em: 25/08/2020

Publicado em setembro de 2020 
